\title{
NTC Thermistor Performance and Linearization of its Temperature- Resistance Characteristics Using Electronic Circuit
}

\author{
K.T. Aminu, A. G. Jumba, A. A. Jimoh, A. Shehu, B. D. Halilu, S. A. Baraza, \\ A. S. Kabiru, and M. A. Sule \\ Department of Electrical Engineering \\ Abubakar Tatari Ali Polytechnic Bauchi \\ Nigeria
}

\begin{abstract}
This paper critically discusses the performance of an NTC thermistor sensor in the temperature range $20^{\circ} \mathrm{C}$ to $85^{\circ} \mathrm{C}$ and provides a technique for linearization of the temperature sensed by the thermistor. The linearization was achieved by utilizing Wheatstone bridge electronic circuitry which responds to the thermistor and produces an output which is an exponential function of the temperature sensed by the thermistor sensor. A further simple and low-cost electronic circuitry responds to such output and converts the resistance measurement to provide a signal which represents the temperature. Moreover, the Wheatstone bridge signal conditioning circuitry was designed to have $0-100 \mathrm{mV}$ output voltage within the considered temperature range. The physical characteristics of the thermistor (constant $A$ and $b$ ) were found to be $4.0015 \times 10^{-5} \pm 0.2956 \times 10^{-5} \Omega$ and $3514.8 \pm 11.6 \mathrm{~K}$ respectively. The result also shows that the percentage nonlinearity was as low as 1.7 and a sensitivity value of $1.5661 \mathrm{mV} / \mathrm{K}$ was found for the thermistor, but the resolution of this thermistor sensor is $2{ }^{\circ} \mathrm{C}$. However, the percentage of nonlinearity obtained was in agreement with the theoretical percentage nonlinearity.
\end{abstract}

Keywords: Temperature measurement, Thermistor sensor, Practical design, linearization, Nonlinearity.

\section{INTRODUCTION}

In the recent decades, thermistor has been widely used for temperature measurement among a variety of applications. Nevertheless, however, one of the most significant discussions in thermistor is that it is a piece of semiconductor made from oxides of metal such as cobalt, iron, nickel, manganese, chromium and uranium pressed in into small wafer, disk, bead or other shape fused at high temperatures and ultimately coated with glass or epoxy and produced in the form of thick films, thin films and pellets [1] [2]. There are two types of thermistors namely: PTC (Positive Temperature Coefficient) and NTC (Negative Temperature Coefficient). The PTC thermistor has its resistance increasing with increasing temperature. Conversely, the NTC thermistor has its resistance decreasing with increasing temperature. However, the NTC thermistors are the most commonly used type than the PTC thermistors, particularly for temperature applications [3] [4]. Figure 1 depicts the NTC thermistor Resistance-Temperature characteristics curve.

As far we know, thermistor sensors are very useful temperature measuring devices because of their high sensitivity, high stability, repeatability, and large temperature coefficient of resistance so that variations in the thermistor's resistance provide a relatively high sensitive temperature sensing operation. On the other hand, one of the significant problems in using thermistors, however, is that the relationship between the resistance and that of the temperature is a non-linear one although such relationship can be expressed by a well known equation. Therefore, in order to make use of thermistors over a wide range of temperature variations it is been found effective to pre-determine the resistancetemperature relationship in accordance with such equation over a relatively wide range of temperatures and then the 
constants in the equation are pre-stored. Consequently, a particular temperature can be readily obtained by firstly determining the resistance of the thermistor element and then the equation is invoked [5].

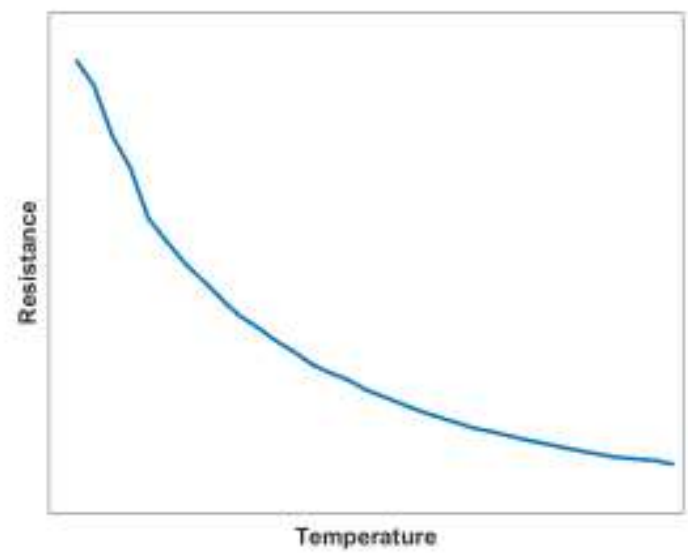

\section{Figure 1: NTC Thermistor Resistance-Temperature Characteristics}

However, to the best of authors' knowledge, the major trade off for the high resistance and sensitivity of the thermistor is its relatively limited operating range and highly nonlinear output [5]. Depending on the thermistor's configuration, upper ranges are typically limited to around $573.15 \mathrm{~K}$. Notwithstanding; the thermistor has been used primarily for high-resolution temperature measurements over limited temperature ranges. Nevertheless, continuing improvements in thermistor stability, accuracy and interchangeability have prompted increased usage of thermistor in all type of industries [5].

A considerable amount of literature has been published on thermistors. These studies have revealed the simplicity and low cost characteristics of thermistors in the design of temperature measurement system. For example, Munifah, et al. [6] have designed temperature measuring instrument using NTC thermistor of $\mathrm{Fe}_{2} \mathrm{TiO}_{5}$ sensor based on microcontroller ATMEGA 328. The NTC is assembled in parallel with a fixed resistor and the assembled on ICLM74 and microcontroller ATMEGA 328. They varied the magnitude of the resistor at $1 \mathrm{M} \Omega, 2 \mathrm{M} \Omega$ and $3 \mathrm{M} \Omega$ with each resistor having a tolerance value of $0.06688 \mathrm{M} \Omega /{ }^{\circ} \mathrm{C}, 0.0133 \mathrm{M} \Omega /{ }^{\circ} \mathrm{C}$ and $0.0219 \mathrm{M} \Omega /{ }^{\circ} \mathrm{C}$ respectively. Similarly, Jack, et al. [7] have designed a simple measurement system using thermistor for industrial application. From their design they have achieved an output range of $0.155 \mathrm{~V}-1.055 \mathrm{~V}$, percentage nonlinearity as low as $0.16 \%$, a sensitivity of $0.0367 \mathrm{~V} /{ }^{\circ} \mathrm{C}$ and resolution of $1{ }^{\circ} \mathrm{C}$. However, the contribution of this current study is obvious as the resulting outcomes can be capitalized as guidelines to the design of temperature measurement systems using thermistor sensors.

Nevertheless, however, the thermistor, being a temperature sensitive element has its resistance varies with temperature according to the following empirically determined relationship often referred to as the Steinhart-Hart equation given in Equation (1)

$$
R_{T}=A e^{\frac{\beta}{T}}
$$

Where in Equation (1) $R_{T}$ is the resistance of the thermistor at temperature $T, A$ Resistance as $T$ tends to infinity $(\Omega)$, $\beta$ is the material constant $(\mathrm{K})$ and $T$ is the temperature in degrees Kelvin $(\mathrm{K})$, equals to $T\left({ }^{\circ} \mathrm{C}\right)+273.15$. However, to achieve linearization in the form of Equation (2), a Wheatstone bridge circuit having a thermistor and a resistive network has been used in this study to provide the linearization of the resistance-temperature characteristics curve over the temperature range [5] [8]. It should be noted, however, that the Wheatstone bridge circuit is also used to provide the signal conditioning required for the thermistor signal. 


$$
\ln R_{T}=\ln A+\frac{\beta}{T}
$$

\section{METHODOLOGY}

\subsection{Materials}

Thermistor, thermometer (liquid in glass, $-10{ }^{\circ} \mathrm{C}-110{ }^{\circ} \mathrm{C}$ ), soldering iron, magnetic stirrer, an electromagnetic hot plate with an attached retort stand, beaker, digital multi-meter, test-tube, cotton wool, safety goggle, pros kit, connecting wires, test-tube, heat gun, insulating sheath, water, ice, cello tape, an electronic circuit board (vero board), lead sucker, single output Dc power supply $(0-30 \mathrm{~V}, 30 \mathrm{~A})$, Digital multimeters, plywood piece, standard resistors $(1 \mathrm{~K} \Omega, 8.2 \mathrm{~K} \Omega, 1.8 \mathrm{~K} \Omega$ and $390 \Omega)$.

\subsection{Methods}

An experimental investigation will be conducted to explore the relationship that exists between the thermistor's resistance and temperature. A snap shot of the thermistor sensor, location and the entire prototype measurement system is shown in Figure 2. The thermistor was a disc thermistor with coating generally measuring $2.5 \mathrm{~mm}$ to 3.8 $\mathrm{mm}$ in diameter. The thermistor leads are connected to the test clip and the thermistor is immersed in the beaker to the depth that will provide best test results usually obtained by trial and error procedure. While testing, be careful no to immerse the test clip in the water because the added mass may disturb the beaker's equilibrium temperature. In addition extra care must be taken throughout the testing process to ensure the resistance measurements have the best repeatability and lowest uncertainty possible. This effort will prevent the introduction of unwanted errors that would distort the actual drift characteristics of the thermistor. Moreover, always ensure to place the eyes vertically at right to the thermometer scale when taking readings, to avoid errors due to parallax. In order to determine the characteristics of the NTC thermistor, special consideration is given to the room temperature, the temperature range in step variation of $2{ }^{\circ} \mathrm{C}$ and the thermistor's resistance. The thermistor is mounted with the thermometer on the retort stand clamped together with the test tube and a cotton wool in between to prevent heat from escaping to the atmosphere. Additionally, a plywood piece is used to cover the beaker top for the same previous purpose. The beaker of water containing the stirrer is placed on the electromagnetic hot plate which is connected to a DC power supply source. In this stage, the design make use of excel spreadsheet and active electronic circuit using Wheatstone bridge to accomplish the task.

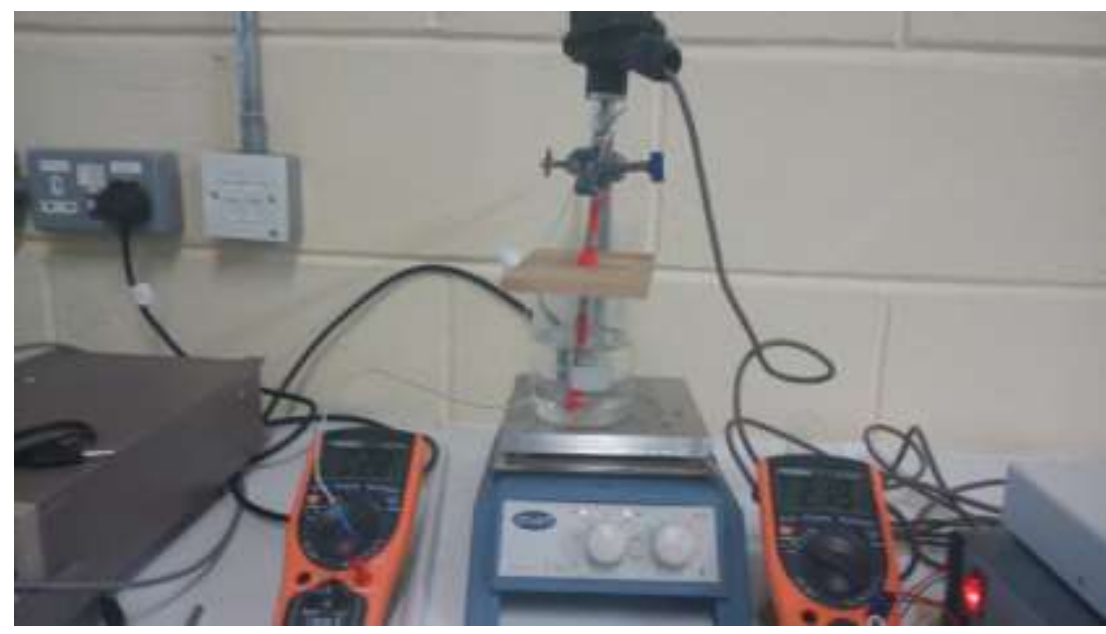

Figure 2: Temperature Measurement System Based on Thermistor

In the second part of the experimental investigation campaign, the design of signal conditioning circuit based on Wheatstone bridge using a numerical method will be considered. This is the linearization method employed to linearize the output voltage of the thermistor as a function of the input temperature. It necessary that before the circuit 
is implemented, the value of the standard resistors available in the laboratory is measured. Excel spreadsheet is adopted for this computation. The measured and the computed results of the resistance values will be compared with that of the numerical design model. Figure 3 depicts the bridge circuit used as signal conditioning circuit for the thermistor.

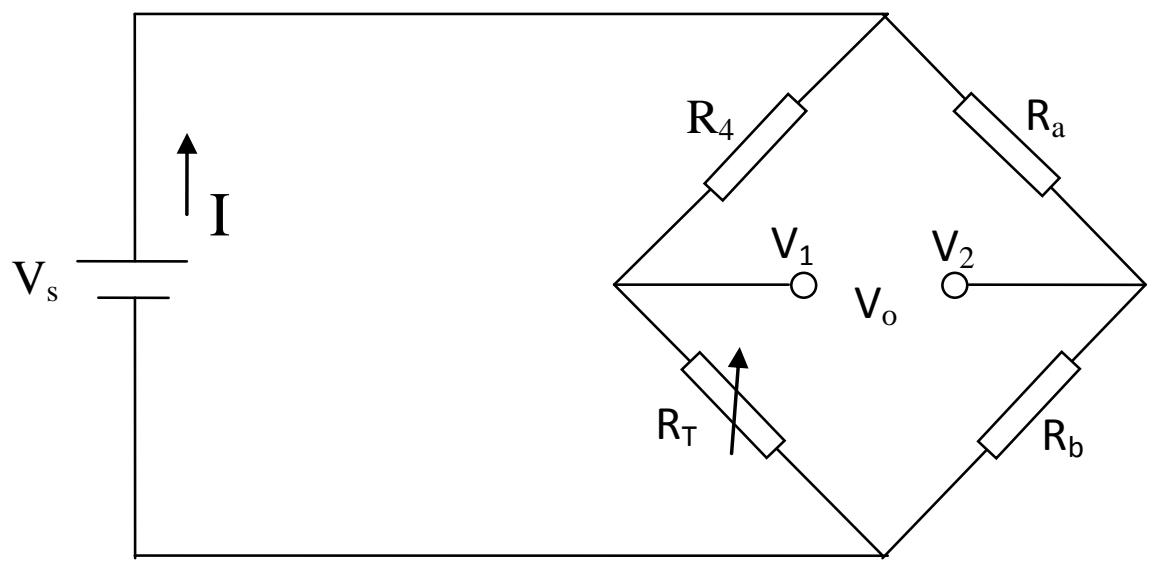

Figure 3 Bridge Circuit used in

linearizing the thermistor

\section{EXPERIMENTAL SETUP AND PROCEDURE}

A series of experimental trials were carried using the setup shown in Figure 2. The room temperature was read and recorded. Similarly, the thermistor resistance at the ambient temperature was read and recorded. The thermistor was soldered to two wires and then insulated using the insulating sheath and heat from the heat gun was applied to fasten the insulating sheath to the thermistor wires. The two wires were then connected to the digital multi-meter. The thermistor was then tied to the thermometer using the cello tape, and usually lags behind the thermometer because of its high sensitivity to temperature. It was then put inside the test-tube which was clamped on the retort stand, and immersed in a beaker containing water. The beaker was already half-filled water and placed on the magnetic stirrer hot plate. The magnetic stirrer hot plate was switched on and heating process begins. At intervals of $2{ }^{\circ} \mathrm{C}$, corresponding values of resistance of the thermistor for a temperature range of $20{ }^{\circ} \mathrm{C}-85{ }^{\circ} \mathrm{C}$ (temperature increasing) and temperature range $85{ }^{\circ} \mathrm{C}-20{ }^{\circ} \mathrm{C}$ (temperature decreasing) were recorded.

\section{RESULTS AND DISCUSSION}

\subsection{Characterization of the Thermistor}

The resistance of the thermistor at room was measured as $\mathrm{R}_{25}{ }^{\circ} \mathrm{C}=5.12 \mathrm{~K} \Omega$. Subsequent readings for the thermistor resistance for both temperature increasing and temperature decreasing were taken and either of the two was plotted to give the thermistor resistance-temperature characteristic curve as shown in Figure 4. The discussion of the results begins with an analysis in order to characterize the NTC thermistor. The characterization is performed to obtain the thermistor constants $\beta$ and $A$ respectively. 

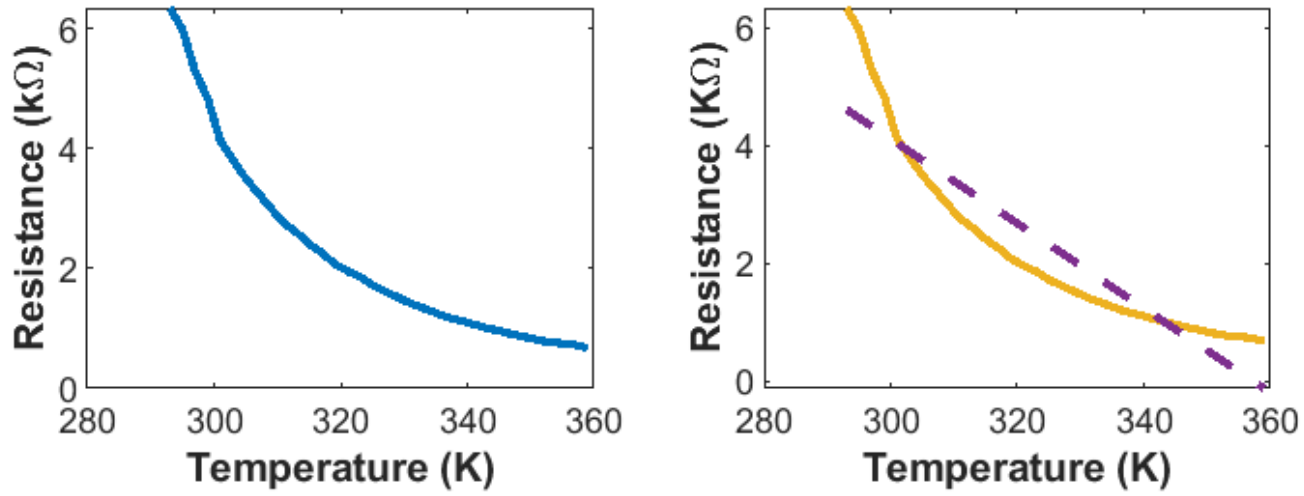

\section{Figure 4: Thermistor Resistance-Temperature Curve (left) and Thermistor Resistance-Temperature Curve} with trend line

Figure 4 is very helpful in understanding the concept of linearization. As can be seen qualitatively in Figure 4, Equation (1) set forth above approximately represents a decaying exponential curve. The trend line is inserted to facilitate the computation of the sensitivity and the percentage nonlinearity using Equation (3) and Equation (4) respectively.

$$
\text { Sensitivity }=\frac{C \square \text { ange in Resistance }}{C \square \text { ange in Temperature }}
$$

$$
\text { Nonliniearity }=\frac{T \square \text { e maximum deviation in } t \square e t \square \text { ermistor Resistance Value }}{\text { output span (max }-\min ) \text { of } t \square e t \square \text { ermistor resistance }}
$$

From Equation (3), the sensitivity of the thermistor was found to be $-0.0719 \mathrm{~K} \Omega / \mathrm{K}$ and the percentage nonlinearity was found to be $30.45 \%$ which further evidenced that exponential relationship that exists between the resistance and the temperature of the thermistor, thus depicting a highly nonlinear relationship. It should be noted that within the measuring system, the temperature of the system usually rises and fall and thus introducing the temperature hysteresis effect. The hysteresis setting is the amount of narrowness and wideness of the temperature reading. Therefore, plotting both the values of resistance with increasing temperature and decreasing temperature against the temperature depicts the hysteresis effect of the thermistor. This effect is depicted in Figure 5. 
International Journal of Advances in Scientific Research and Engineering (ijasre), Vol 6 (8), August -2020

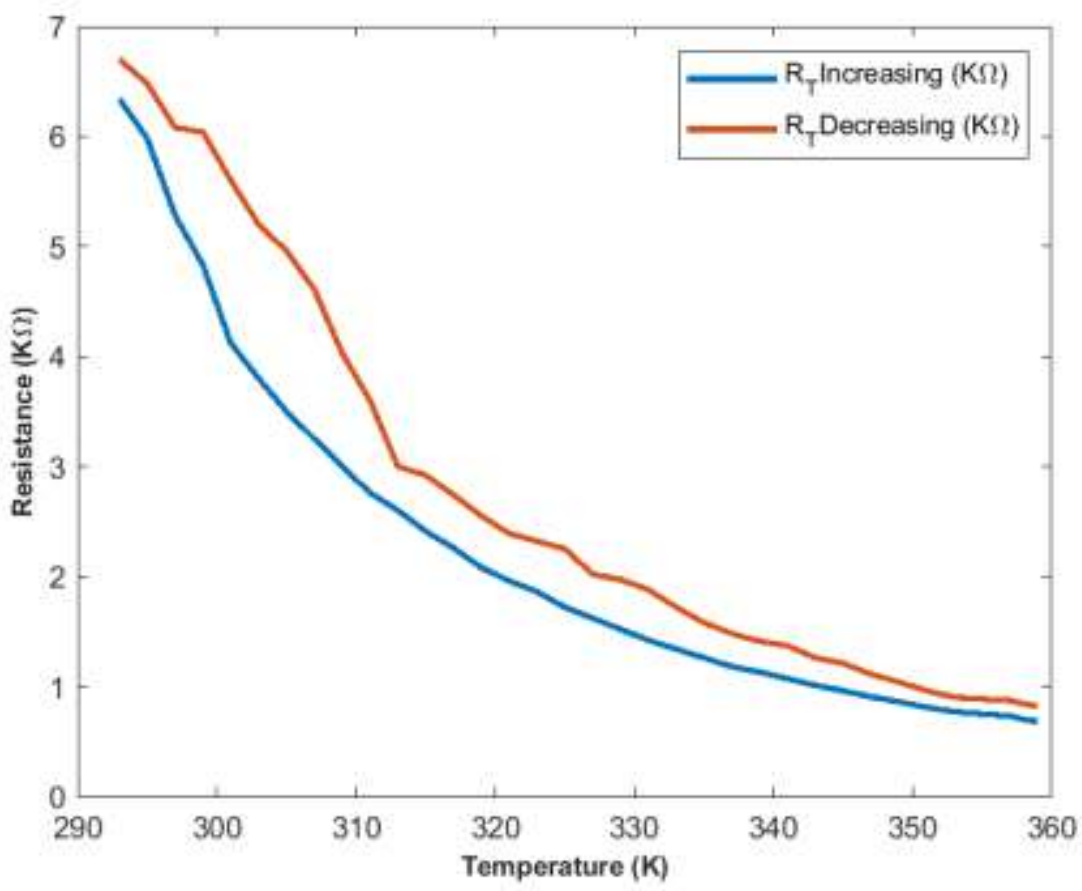

Figure 5: Hysteresis Effect of a Thermistor

It is apparent from this figure that the percentage of the temperature hysteresis effect was computed using Equation (5) and this value was found to be $20 \%$.

$$
\text { Hysteresis }=\frac{\text { Maximum deviation }}{\text { Output span }} * 100
$$

Now, if the representation of $\ln R_{T}$ in Equation (2) is shown graphically as a function of $\frac{1}{T}$, it is seen that such a curve is relatively linear, as shown in Figure 6 and Figure 7 respectively. While the curves in Figure 6 and 7 are shown as ideally linear, an actual curve may deviate slightly as depicted by the dashed line. However, Equation (1) is therefore not a perfect exponential relation of $R_{T}$ vs $T$ and accordingly is not a linear function of $\ln R_{T}$ vs $\frac{1}{T}$. The graph of $\ln R_{T}(\mathrm{~K} \Omega)$ for both the temperature increasing and decreasing against inverse temperature $\left(\frac{1}{T}\right)$ was plotted in Figure 6 and Figure 7 respectively and a trend line was inserted so as to obtain the values of the thermistor constants $A$ and $\beta$. 
International Journal of Advances in Scientific Research and Engineering (ijasre), Vol 6 (8), August -2020

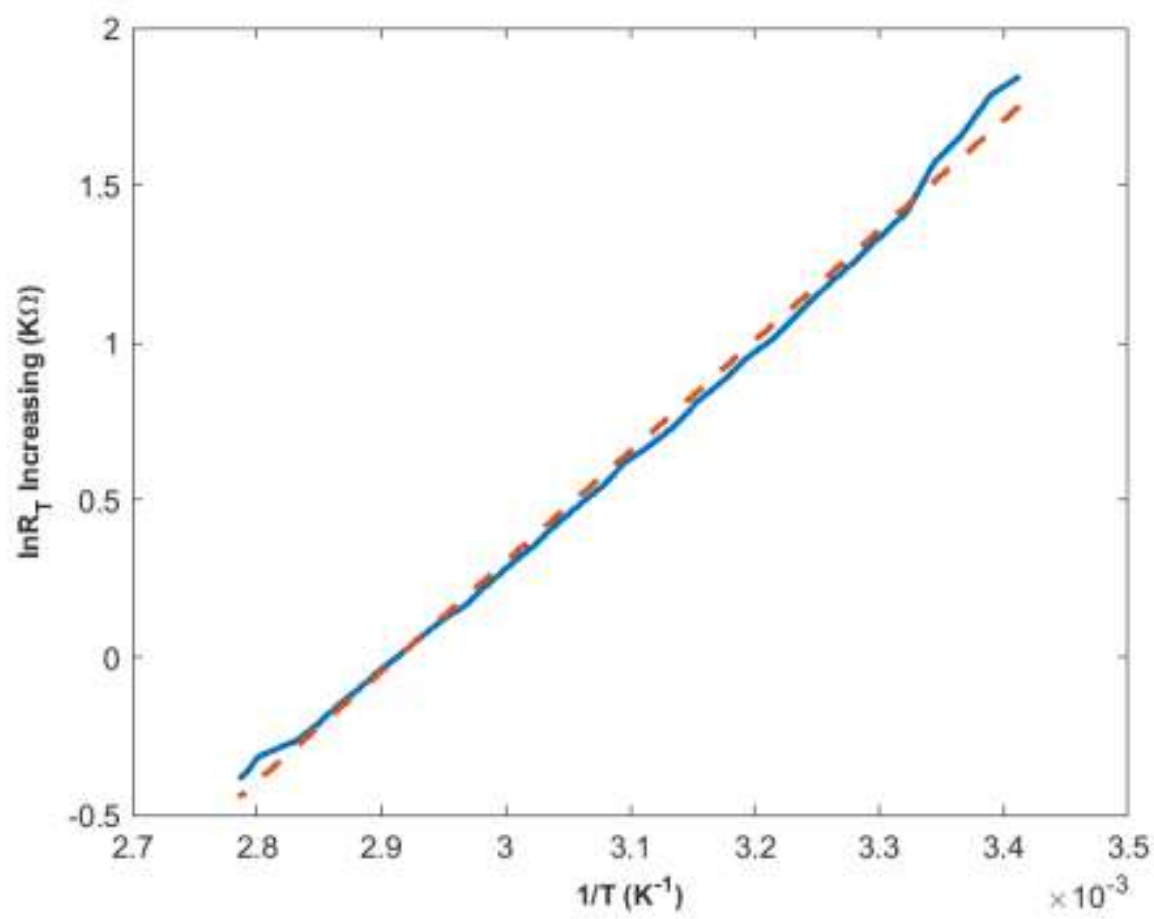

Figure 6: The graph of $\ln R_{\text {temp.increasing }}(\mathrm{K} \Omega)$ against $1 / T\left(\mathrm{~K}^{-1}\right)$

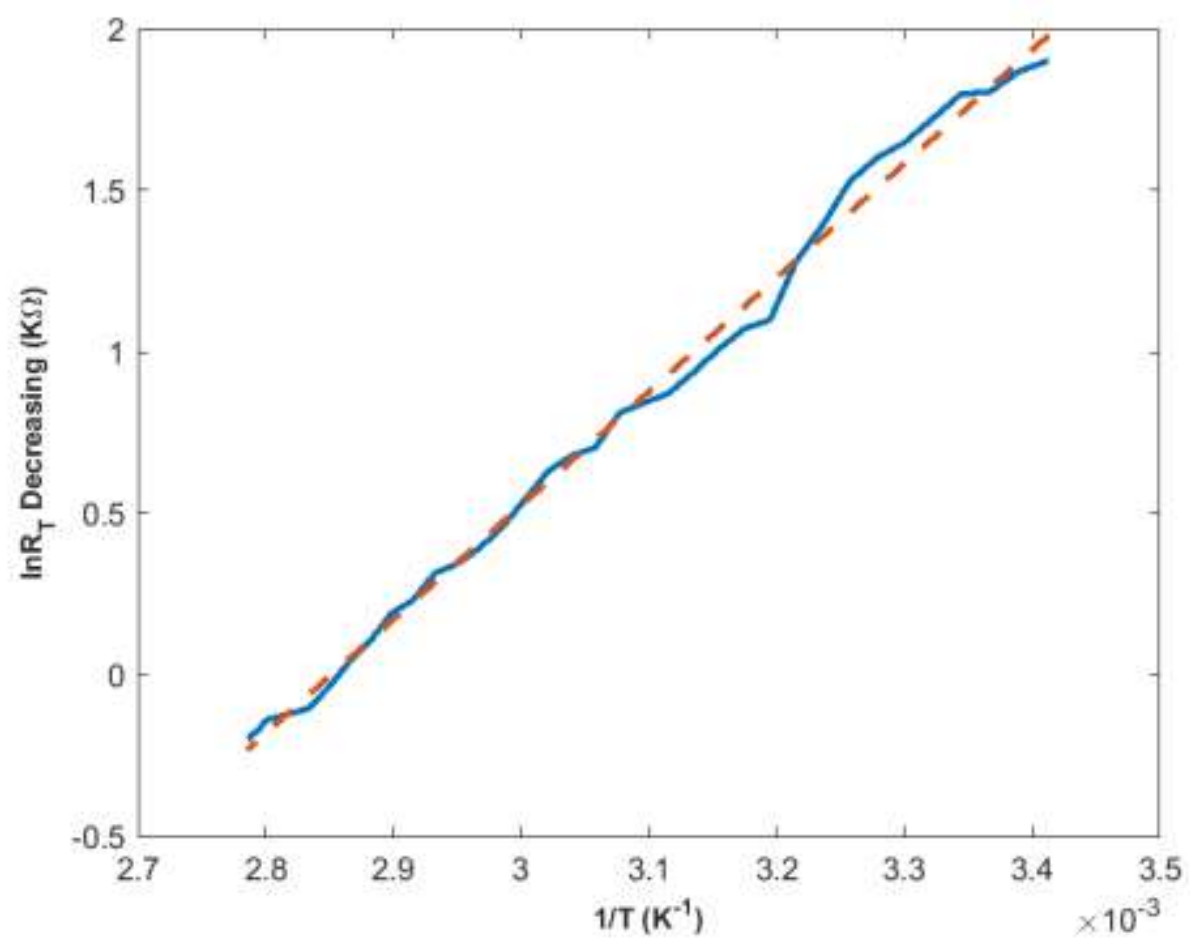

Figure 7: The graph of $\ln R_{\text {temperature }}$ decreasing against $1 / T\left(K^{-1}\right)$

From Figure 4, to linearize the nonlinear relationship of the thermistor resistance with temperature, Equation (1) is manipulated by taking the natural logarithm of the equation and the operation yields Equation (2). Recalling the equation of a straight line (linear) graph i.e,

$$
Y=M x+C
$$

\section{DOI: 10.31695/IJASRE.2020.33854}


Comparing Equation (2) and Equation (6) yields that, $\ln R_{T}$ is linearly dependant on $\frac{1}{T} \cdot \beta$ is the slope of the straight line and $\ln A$ represent the intercept. Also, by Equation (2) it is easy to see that the physical characteristics of the thermistor (constants $A$ and $\beta$ ) can be obtained.

From Figure 6,

The slope $\beta=3503.203 \mathrm{~K}$

$\ln A=-10.203$, this implies that $A=\mathrm{e}^{-10.203}=3.7059 \times 10^{-5} \Omega$

Also From Figure 7,

The slope $\beta=3526.4 \mathrm{~K}$

$\ln A=-10.055$, which also implies that $A=\mathrm{e}^{-10.055}=4.2970 \times 10^{-5} \Omega$

The best result of $\beta$ and $A$ can be obtained by taking the average of the two quantities $\beta$ and $A$ (i.e taking uncertainty in measurement into consideration)

$$
\begin{aligned}
\beta_{\text {best }}=\frac{3503.203+3526.4}{2} \\
=3514.8 \pm 11.6 \mathrm{~K} \\
A_{\text {best }}=\frac{3.7059 \times 10^{-5}+4.2970 \times 10^{-5}}{2} \\
=4.00145 \times 10^{-5} \pm 0.2956 \times 10^{-5} \Omega
\end{aligned}
$$

It could be deduced that from Figure 4, the thermistor characteristics is nonlinear. It was also observed that the thermistor's resistance changes rapidly for every $2{ }^{\circ} \mathrm{C}$ temperature change; this has also confirm the assertion that thermistor is very sensitive to temperature. The thermistor resistances were different for the same temperature values when the temperature was increasing and when it was decreasing which indicates the hysteresis effect of the thermistor (Figure 5). Figure 6 and Figure 7 show that the linearization of the thermistor characteristics has led to the determination of the best values for the thermistor constants $(\beta$ and $A)$.

\subsection{Linearization Method}

From Figure 4, 6 and 7, it has been found in accordance with this study that, by making some minor modifications, it is possible to obtain a more perfect exponential relation of $R_{T}$ with $T$, or equivalently, a nearly perfect linear relation of $\ln R_{T}$ with $T$. These modifications may be performed by utilizing a Wheatstone bridge circuit shown in Figure 3 wherein a thermistor sensor having resistance $R_{T}$ connected in series with a resistor having resistance $R_{4}$ has shunt a resistor having resistance from the series combination of $R_{a}$ and $R_{b}$ in parallel therewith and a supply voltage $V_{S}$ in series with the thermistor. The thermistor resistance $R_{T}$ for the various temperatures were computed using Equation (1) where in the equation $\beta=3514.8 \pm 11.6 \mathrm{~K}$ and $A=4.00145 \times 10^{-5} \pm 0.2970 \times 10^{-5} \Omega$. The results obtained for $R_{T}$ were recorded. Since the design was based on bridge circuit, then from Figure 3;

$$
V_{1}=\frac{R_{T}}{R_{4}+R_{T}} * V_{S}
$$

Where $V_{1}=$ output voltage of the thermistor, $V_{S}=$ supply voltage, which controls the output range $(0-100 \mathrm{mV}), R_{4}=$ resistance in series with the thermistor and is $R_{4}$ that control the linearization, $R_{T}=$ thermistor resistance at a given temperature. Initially, for design purposes, the value of $R_{T}$ was taken to be $10 \mathrm{~K} \Omega$ and the value $V_{S}$ as $0.21 \mathrm{~V}(210 \mathrm{mV})$ and the corresponding values of $V_{1}$ at different temperatures were computed and plotted as shown in Figure 8 


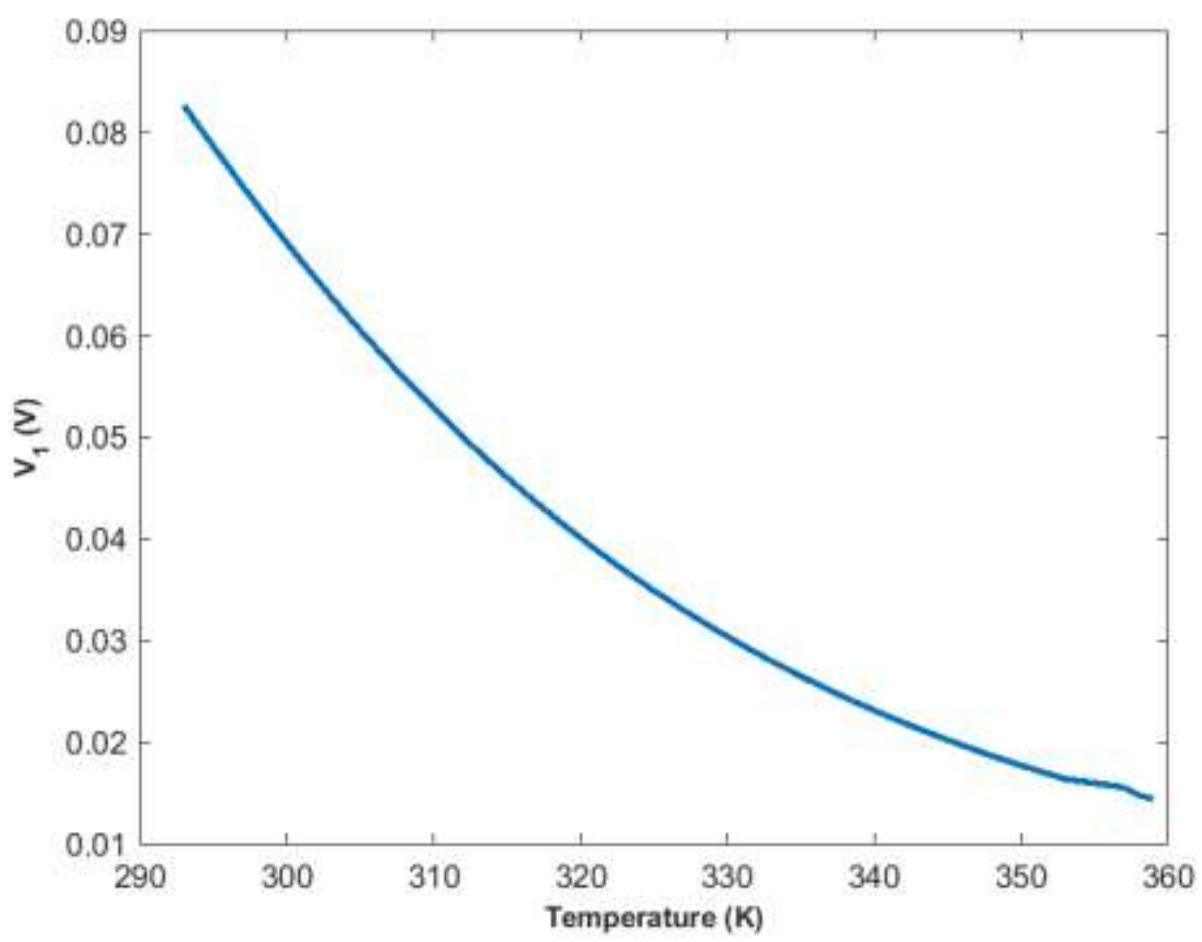

Figure 8: The Graph of Thermistor Voltage $\mathrm{V}_{1}$ against Temperature

As it can be seen from Figure 8 the relationship is clearly nonlinear and to find the nonlinearity, a terminal line need be defined and this line has a characteristics indicated by Equation (6). In Equation (6), $Y=\mathrm{V}_{\text {terminal }}$ voltage (V), $M=$ slope $(\mathrm{V} / \mathrm{K}), X=$ input temperature $(\mathrm{K})$ and $C=$ intercept $(\mathrm{V})$. The values of $R_{4}, V_{\mathrm{S}}, M$ and $C$ were referenced absolutely in the Exel spreadsheet workspace, such that a change in $R_{4}$ or $V_{\mathrm{S}}$ (during optimization) will affect the whole computation process. However, for illustration purpose the values of $M$ and $C$ were computed from Figure 8. In the computation process, the intervals $(0.082618679 \mathrm{~V}, 293 \mathrm{~K})$ and $(0.014371416 \mathrm{~V}, 358 \mathrm{~K})$ were considered.

$$
\begin{aligned}
& M=\frac{0.014371416-0.082618679}{358-293} \\
& \therefore M=-0.001049957 \mathrm{~V} / \mathrm{K}
\end{aligned}
$$

And $\mathrm{C}$ considering either of the interval

$$
\begin{aligned}
& 0.082618679=-0.001049957 * 293+\mathrm{C} \\
& \therefore \quad C=0.39025608 \mathrm{~V}
\end{aligned}
$$

The $V_{\text {terminal }}$ was then computed using the above equation at different temperatures and the result was plotted as shown in Figure 9. 


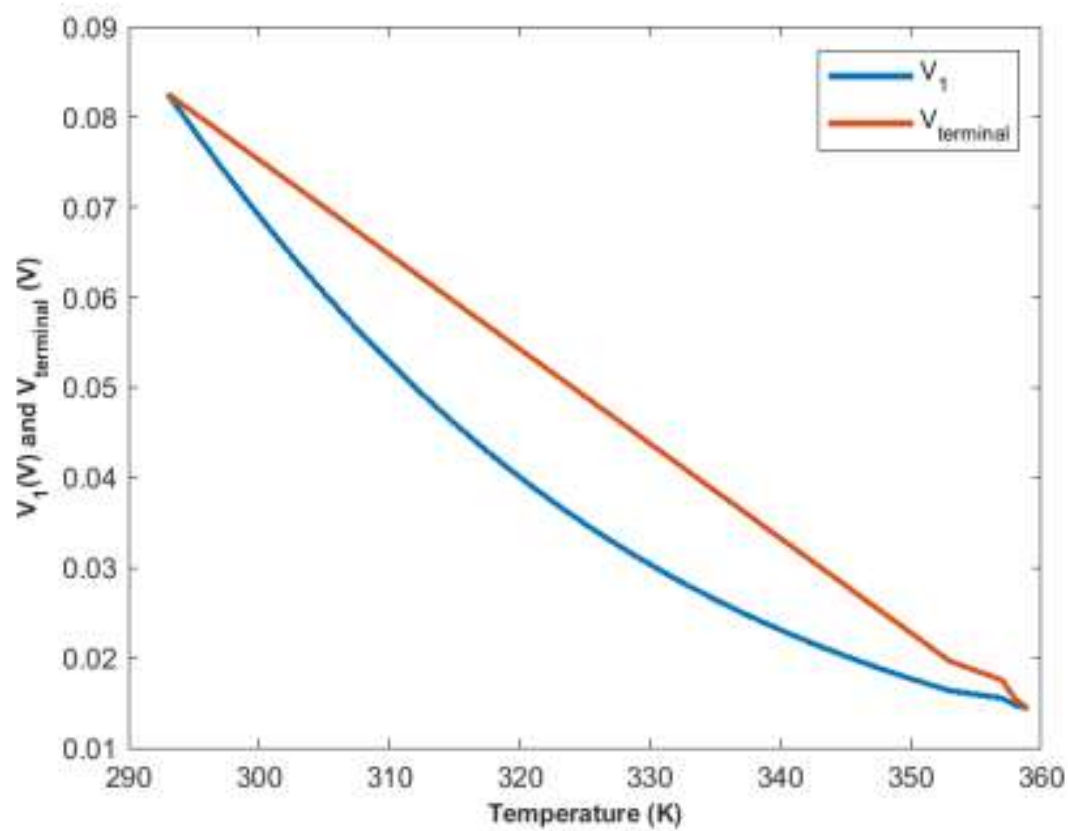

Figure 9: The graph of $V_{1}$ and $V_{\text {terminal }}$ vs Temperature

As Figure 9 shows, the relationship between $V_{1}$ and $V_{\text {terminal }}$ at different temperatures was seen; the design processes involve optimizing the values of $R_{4}$ within the standard values until the best linearity relationship is achieved. Since it is $R_{4}$ that determines the linearity, then $V_{\mathrm{S}}$ determines the desired output range for the thermistor (i.e $0-100 \mathrm{mV}$ ). The optimization for $R 4$ and $V_{\mathrm{S}}$ was done using the Excel spreadsheet (i.e manipulating $R_{4}$ and $V_{\mathrm{S}}$ and viewing until the best linearity is achieved). The best linearity relationship was achieved at $R_{4}=1.415 \mathrm{~K} \Omega$ and $V_{\mathrm{S}}=0.21 \mathrm{~V}(210 \mathrm{mV})$. The percentage nonlinearity is computed using Equation (4). The corresponding values for $V_{1}, V_{\text {terminal }}$ at various temperatures were computed and plotted as shown in Figure 10.

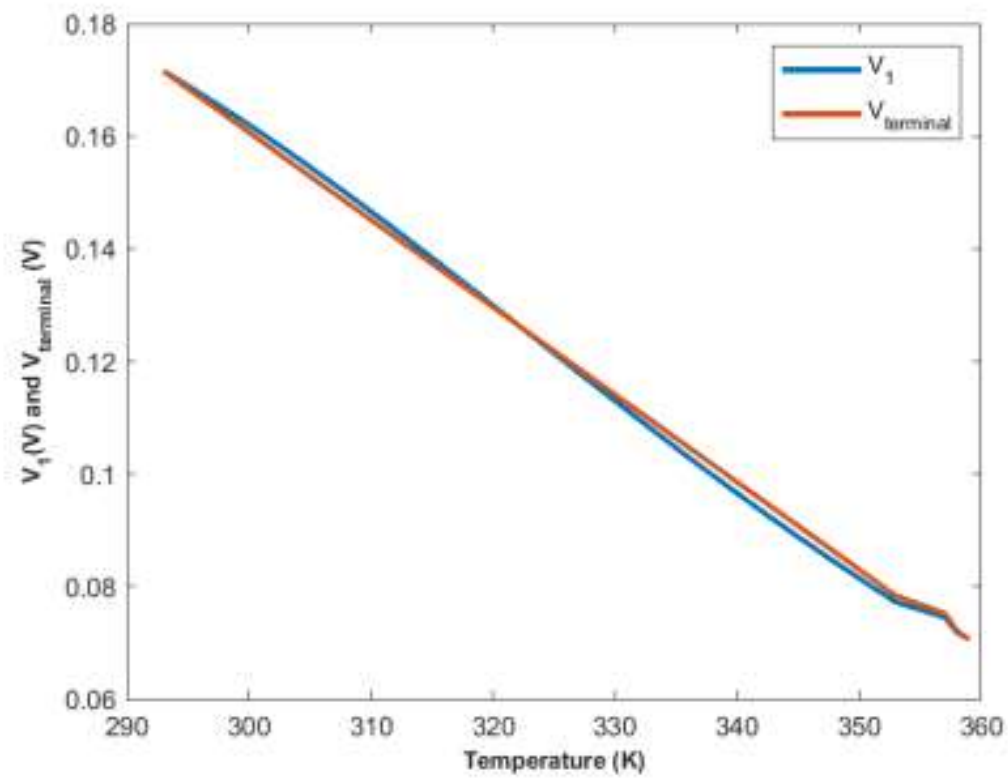

Figure 10: The graph of $V_{1}$ and $V_{\text {terminal }}$ vs Temperature

Similarly, the values of percentage nonlinearity computed using Equation (4) at various temperatures was plotted as depicted in Figure 11. 


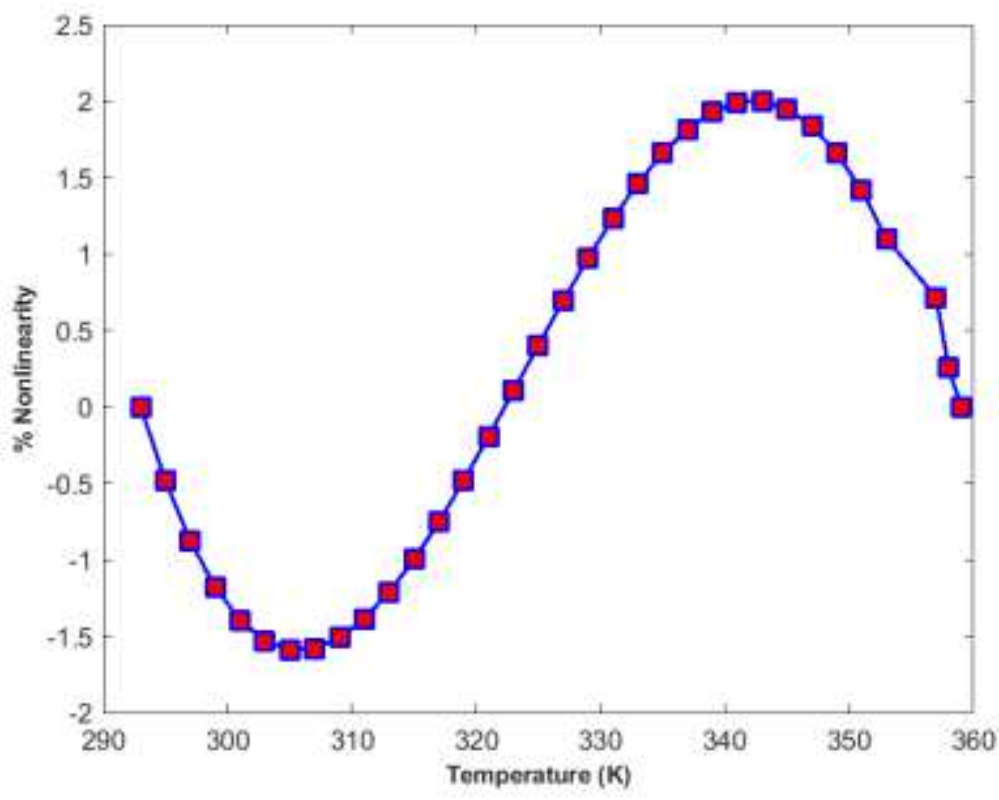

Figure 11: The graph of \% Nonlinearity vs Temperature

The most striking result to emerge from this analysis is that, from Figure 11 the maximum percentage nonlinearity was found to be $2 \%$. Practically, however, achieving the value of $R_{4}=1.415 \mathrm{~K} \Omega$ was not successful, because of the limitation placed on implementing its value (i.e only a combination of two standard resistors, either series or parallel combination was allowed). Therefore, a near standard value of $R_{4}=1.39 \mathrm{~K} \Omega$ (i.e $390 \Omega$ and $1 \mathrm{~K} \Omega$ in series) was considered.

The new values for $V_{1}$,Vterminal and $\%$ nonlinearity at the various temperatures were computed and plotted as shown in Figure 12 and Figure 13 respectively.

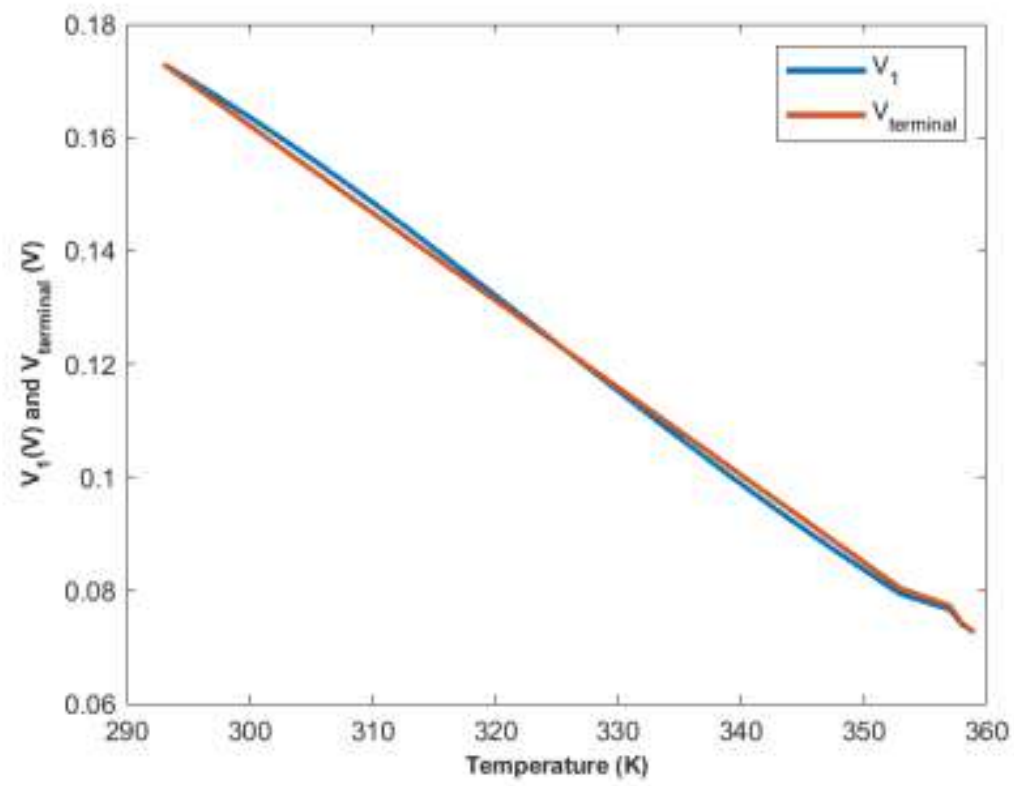

Figure 12: The graph of $V_{1}$ and $V_{\text {terminal }}$ vs Temperature 


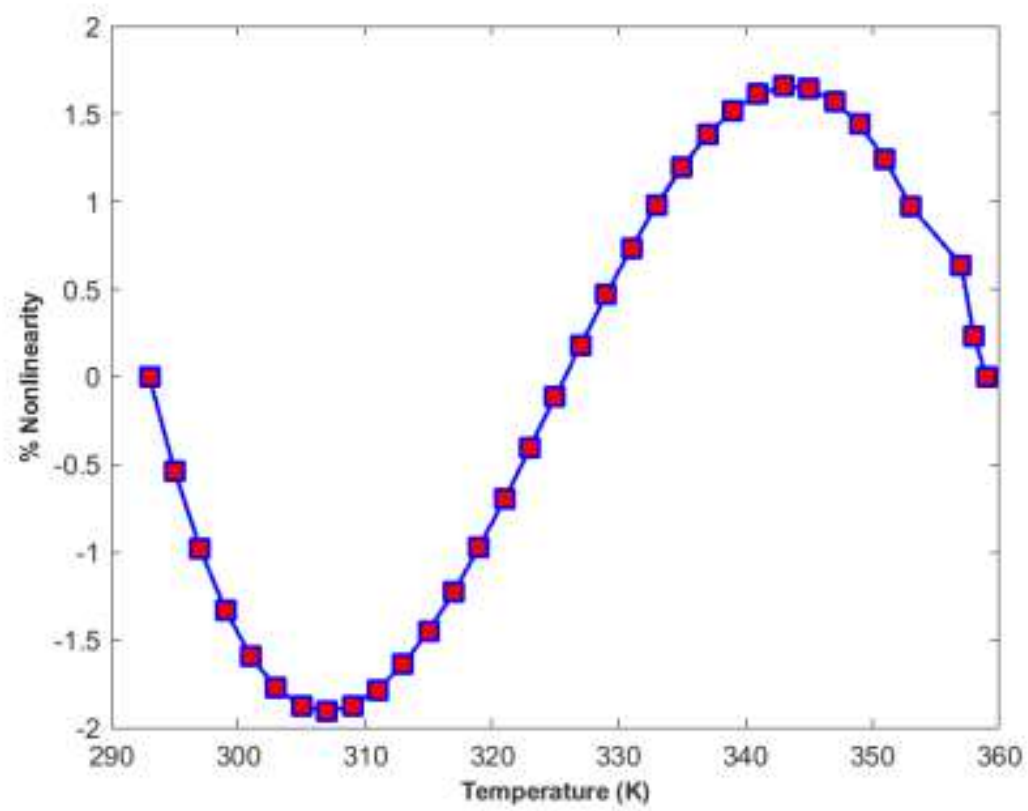

Figure 13: The graph of \% Nonlinearity vs Temperature

Surprisingly, it has been observed that, from Figure 13 the maximum percentage nonlinearity was found to decrease from $2 \%$ to $1.7 \%$ when the value of $R_{4}$ was taken to be $1.39 \mathrm{~K} \Omega$.

Now, the design of $R_{\mathrm{a}}$ and $R_{\mathrm{b}}$ was achieved when the bridge was balanced. However, at balance;

$$
\begin{gathered}
V_{2}-V_{1}=0 \\
V_{2}=V_{1}
\end{gathered}
$$

Similarly,

$$
\frac{R_{4}}{R_{T}}=\frac{R_{a}}{R_{b}}
$$

And best $R_{4}=1.415 \mathrm{~K} \Omega$, maximum $R_{\mathrm{T}}=6.485934 \mathrm{~K} \Omega$. Substituting these values into Equation (10) yields;

$$
\frac{1.415}{6.485934}=\frac{R_{a}}{R_{b}}
$$

Manipulating Equation (11) yields;

$$
0.21816455=\frac{R_{a}}{R_{b}}
$$

For design purposes, the value of $R_{b}$ was chosen to be $8.2 \mathrm{~K} \Omega$

$$
\begin{aligned}
\therefore R_{\mathrm{a}} & =0.21816455 \times 8.2 \times 10^{3} \\
R_{\mathrm{a}} & =1.78894931 \mathrm{~K} \Omega \\
\sim R_{\mathrm{a}} & =1.8 \mathrm{~K} \Omega \text { (standard) }
\end{aligned}
$$

This gives the value of $R_{\mathrm{a}}=1.8 \mathrm{~K} \Omega$ and $R_{b}=8.2 \mathrm{~K} \Omega$. Now,

\section{DOI: 10.31695/IJASRE.2020.33854}




$$
\begin{gathered}
V_{2}=\frac{R_{b}}{R_{b}+R_{a}} * V_{S} \\
V_{2}=\frac{8.2}{8.2+1.8} * 0.21 \\
\therefore V_{2}=0.1722 \mathrm{~V}
\end{gathered}
$$

The linearity relationship achieved at the value of $R_{4}=1.415 \mathrm{~K} \Omega$ was depicted in Figure 10 and the maximum percentage noninearity was found to be $2 \%$ as seen in Figure 11. Because on the limitation placed on the practical implementation of $R_{4}$, a near standard value of $R_{4}=1.39 \mathrm{~K} \Omega$ was considered, and this changed the linearity relationship to one seen in Figure 12 and the maximum \% nonlinearity to $1.7 \%$ as seen in Figure 11. The best value of $V_{\mathrm{S}}$ was achieved at $V_{\mathrm{S}}=0.21$. Interestingly, however, increasing $V_{\mathrm{S}}$ above this value has the effect of damaging the thermistor, because more current will be flowing through the thermistor. This current will cause the self-heating of the thermistor.

\subsection{Implementation of the Design}

The bridge circuit in Figure 3 realised from the design has $R_{\mathrm{a}}=1.8 \mathrm{~K} \Omega, R_{\mathrm{b}}=8.2 \mathrm{~K} \Omega, R_{4}=1.39 \mathrm{~K} \Omega R_{T}=$ variable dependent on temperature, $V_{\mathrm{S}}=0.21 \mathrm{~V}$. The temperature interval was increased from $2{ }^{\circ} \mathrm{C}$ that was previously used to $5{ }^{\circ} \mathrm{C}$, this is to allow the thermistor to stabilize at the desired temperature before taking reading and this usually takes longer time.

Repeated measurements were taken at temperature $323 \mathrm{~K}$ in order to obtain the best value $V_{\mathrm{o}}$ at that temperature. Thus,

$$
\begin{aligned}
& \frac{54.9+54.1+54.2+54.7+54.2+54.6}{6} \\
= & 54.5 \mathrm{mV}
\end{aligned}
$$

The Standard uncertainty;

$$
\mathrm{S}_{\mathrm{N}}=\frac{\delta_{N-1}}{\sqrt{N}}=\frac{0.3033}{\sqrt{6}}=0.1238
$$

Expanded uncertainty for $95 \%$ confidence;

$$
\begin{aligned}
& =\mathrm{KU} \text { where } \mathrm{U}=0.1238, \mathrm{~K}=2.57 \text { (from distribution table) } \\
& =0.1238 \times 2.57=0.3182
\end{aligned}
$$

$\therefore$ the best result for $V_{\mathrm{o}}$ at that temperature is $54.5 \pm 0.3182 \mathrm{mV}$

The performance test results were plotted as shown on Figure 14 


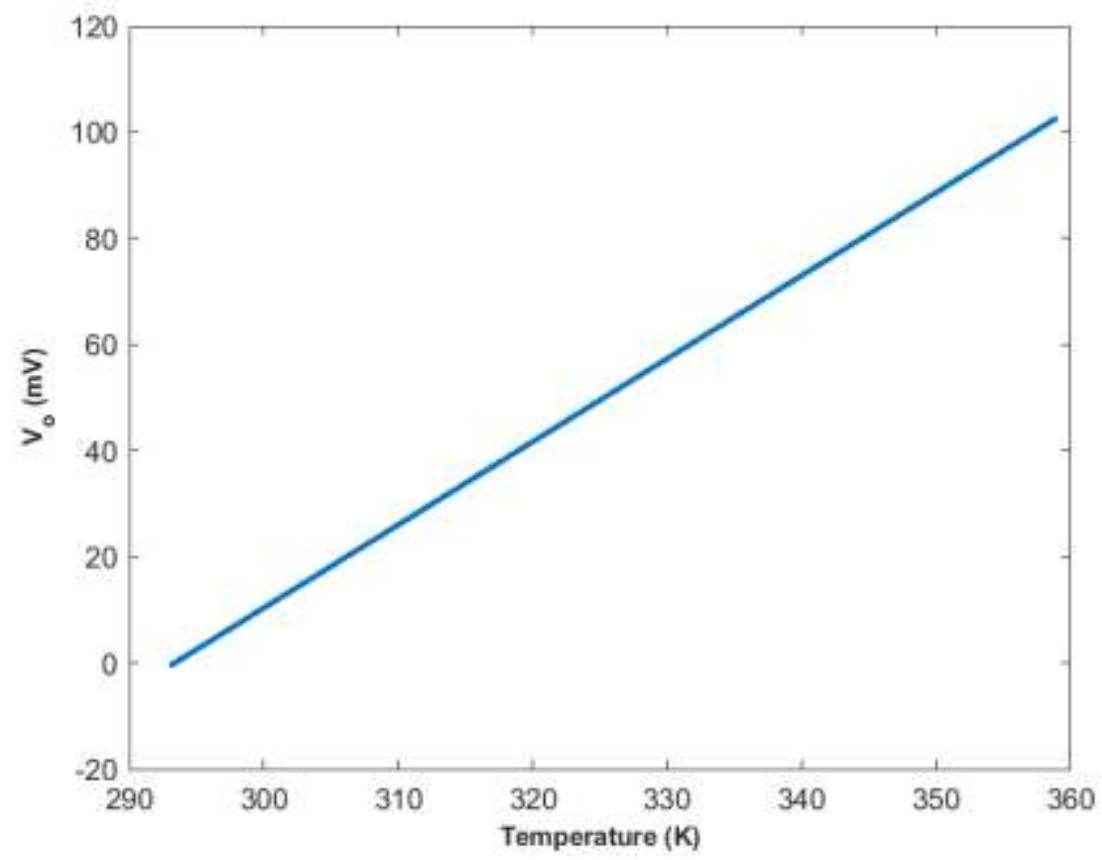

Figure 14: The graph of $V_{\mathrm{o}}$ against Temperature

This figure is quite revealing in some way. The output voltage response of the bridge circuit is relatively closely linear over the temperature range. So long as the temperatures to be measured are confined to that range the output from the thermistor circuitry using the resistance network is a linear function of the thermistor temperature. Additionally, such circuitry will be relatively easy to calibrate.

\section{CONCLUSION}

This study set out to explore the performance of NTC thermistor and the linearization of its resistance-temperature characteristics using electronic circuitry within the temperature range $20{ }^{\circ} \mathrm{C}-85{ }^{\circ} \mathrm{C}$. Interestingly, this study has shown that using the temperature range $20{ }^{\circ} \mathrm{C}-85^{\circ} \mathrm{C}$ we were able to see the thermistor characteristics and determine the best values of the thermistor constants (i.e $\beta=3514.8 \pm 11.6 \mathrm{~K}$ and $A=4.00145 \pm 0.2970 \times 10^{-5} \Omega$ ). The linearization of the thermistor output voltage was achieved by designing a signal conditioning circuit based on Wheatstone bridge circuit whose output voltage was limited to the $0-100 \mathrm{mV}$. The designed circuit was implemented; measurements were taken repeatedly at temperature $323 \mathrm{~K}$ to obtain the best value of the output voltage for appreciation of uncertainty at that temperature. It was found to be $54.5 \pm 0.3182 \mathrm{mV}$. It was also shown that that the percentage nonlinearity was as low as 1.7 and sensitivity value of $1.5661 \mathrm{mV} / \mathrm{K}$ was found for the thermistor, but the resolution of this thermistor sensor is $2{ }^{\circ} \mathrm{C}$. The percentage nonlinearity obtained is in agreement with the percentage nonlinearity commonly obtained (theoretically) during the design of the circuit.

This research has thrown up many questions in need of further investigation. For example, considerable work will need to be done to determine whether the use of high gain negative feedback and zero drift operational amplifier at the output of the thermistor's circuitry (bridge circuit) can improve the output voltage by removing loading effects and DC offsets. Moreover, research is needed to implement the circuit design in such a way as to further reduce the self-heating effect of the thermistor.

\section{REFERENCE}

1. Wiendartun, R. and Fitrilawati, R. E. 2016. The Effect of Sintering Atmosphere on Electrical Characteristics of $\mathrm{Fe}_{2} \mathrm{TiO}_{5}$ Pellet Ceramics sintered at $1200{ }^{\circ} \mathrm{C}$ for NTC thermistor, Journal of Physics: Conference Series 739

2. Zhang, D., Shi, M. J., Chen, L. L. and Ding, S. J. 2013. Designing of Thermistor Digital Thermometers based on unbalanced Electric Bridge, Trans. Tech. Publications, Switzerland, Key Engineering Materials 538, Pp $133-137$ 
3. David, P. 1996. Measuring Temperature with Thermistors - a Turtorial, National Instruments Application Note 065

4. Morris, A. S. 2001. Measurement and Instrumentation Principles, third edition

5. Newman, W.H., Mass, B., Burgess, R.G., and Hudson, N. H. 1992. Temperature Measurement Using Thermistor Elements, Medical Physics, Vol. 10(3), Pp. 327 - 332

6. Munifah, S. S., Risdiana, W., and Aminudin, A. 2019. Design of Temperature Measuring Instrument Using NTC Thermistor of $\mathrm{Fe}_{2} \mathrm{TiO}_{5}$ Based on Microcontroller, Journal of Physics: Conference Series 1280

7. Jack, K. E., Nwangwu, E. O., Etu, I. A., and Osuagwu, E. U. 2016. A Simple Thermistor Design for Industrial Temperature Measurement, IOSR Journal of Electrical and Electronics Engineering, Vol. 11(5), Pp. 57 - 66

8. Chakravarty, R. K., Slater, K., and Fischer, C. W. 1977. Linearization of Thermistor Resistance-Temperature Characteristics Using Active Circuitry, Review of Scientific Instruments, Vol. 48(12), Pp 1645-1649 